\title{
Learning Management System Towards Learner's Independent Learning
}

\author{
Kalthom Husain \\ Faculty of Education \\ International Islamic Uni- \\ versity Selangor \\ Selangor, Malaysia \\ kalthom@kuis.edu.my
}

\author{
Puziah Abd. Wahab \\ Faculty of Education \\ International Islamic Uni- \\ versity Selangor \\ Selangor, Malaysia \\ puziah@kuis.edu.my
}

\author{
Mohd Faeez Ilias \\ Faculty of Education \\ International Islamic Uni- \\ versity Selangor \\ Selangor, Malaysia \\ faeez@kuis.edu.my
}

\author{
Mohd Amin Mohd Noh \\ Faculty of Education \\ International Islamic Uni- \\ versity Selangor \\ Selangor, Malaysia \\ mamn@kuis.edu.my
}

\author{
Mohd Izzuddin Mohd Pisol \\ Faculty of Education \\ International Islamic University Selangor \\ Selangor, Malaysia \\ mohdizzuddin@kuis.edu.my
}

\author{
Fariza Hanan Muhammad \\ Faculty of Education \\ International Islamic University Selangor \\ Selangor, Malaysia \\ farizahanan@kuis.edu.my
}

\begin{abstract}
This paper reports on an ongoing research project at International Islamic University College (IIUCS), Selangor, Malaysia where students from faculty of education are consulted to explicate their experiences utilizing Learning Management System (LMS). LMS is an online learning platform enables students to acquire knowledge with the help of technologies. One focus group interview was conducted with 25 participants from Bachelor of Teaching English as a Second Language degree program. Data extracted from the verbatim was analyzed via thematic analysis. Although the data collected is limited to a small sample, participants had provided insightful feedback, which is informing that LMS is a catalyst towards empowering learners to become independent learner. In an effort to produce quality and independent learners, LMS is seen as a means to assist educators in developing quality online internet based courses and websites as well as to fulfill students' needs in acquiring information anywhere and anytime. It then concludes the adoption of LMS and puts forward suggestions for further research.
\end{abstract}

Keywords: learning management system; affordability; independent learning; focus group, thematic analysis

\section{INTRODUCTION}

The changing landscape in teaching and learning demands for new delivery systems and learning media has become more urgent to universities. In an effort to anticipate the needs of future students to learn independently with the support of new technology, the university developed a learning assessment models. The model can capture the student interest that will allow greater flexibility, independence and learner-centre yet do not diminish students' learning experience. The world in which children grow, learn and interact will have significantly different modes of exchange than those of the previous generation [1]. Learners today are immersed in a variety of educational experiences, both formal and informal. These experi- ences are networked and vibrant which involving instructors at the university to guide students in exploring the world.

The Learning Management System (henceforth LMS) had been emplaced in the IIUCS university as a learning tool to support traditional face-to-face lectures or tutorial. In IIUCS, LMS was given a specific name known MyLMS. LMS as a software application that is supported by web-based technology tools supporting e-learning environment. This application is the infrastructure that supports the achievement of the effectiveness of e-learning. LMS is used to manage the curriculum, training materials, and evaluation tools. Application development leads to the module to track learning activities and assessment results. The LMS framework can empower educators and students using access to information that can alter and shape a student's personalized learning path. LMS helps universities to manage learning activities and competencies. LMS provides access to online courses for which the user registers. Administratively, an LMS makes it easy to enter, track, manage and report on learning activities and competencies in universities due to its afford-abilities.

Six main categories of LMS features are as follows: Firstly, Centralize and automate administration; Secondly, Use self-service and self-guided services; Thirdly, Assemble and deliver learning content rapidly; Fourthly, Consolidate training initiatives on a scalable web-based platform; Fifthly, Support portability and standards; Six, Personalize content and enable knowledge reuse [2].

Self-learning or student-centered learning system and describe a complex theme. This system motivates students to be responsible for learning and help teachers in building the structure of the learning environment. Shifting responsibility for the learning process of teachers to students to enable students' understanding of learning. Self-learning is a contemporary learning model in education. Self-learning is manifested 
by the ability to initiate, monitor, and evaluate the learning process [3].

\section{RESEARCH METHOD}

The qualitative data was obtained from a focus group interview. The focus group interview lasted for two hours. The information disclosed was recorded including to the facial expression and body language. These tapes were transcribed, reviewed and analyzed. Focus group interview was adopted due to the advantages which it holds; synergism where a wide range information was obtained, one participant comments triggers a response from another person, stimulating and excitement increases when participants are in a group, feeling of secure and comfortable when participants answered in the group [4].

The data collected was analyzed using thematic analysis. Thematic analyses seek to unearth the themes salient in a text at different levels, and thematic networks aim to facilitate the structuring and depiction of these topics [5]. Thematic networks systematize are represented as web-like maps depicting the salient themes at each of the three levels and illustrating the relationships between them (see Figure 1).

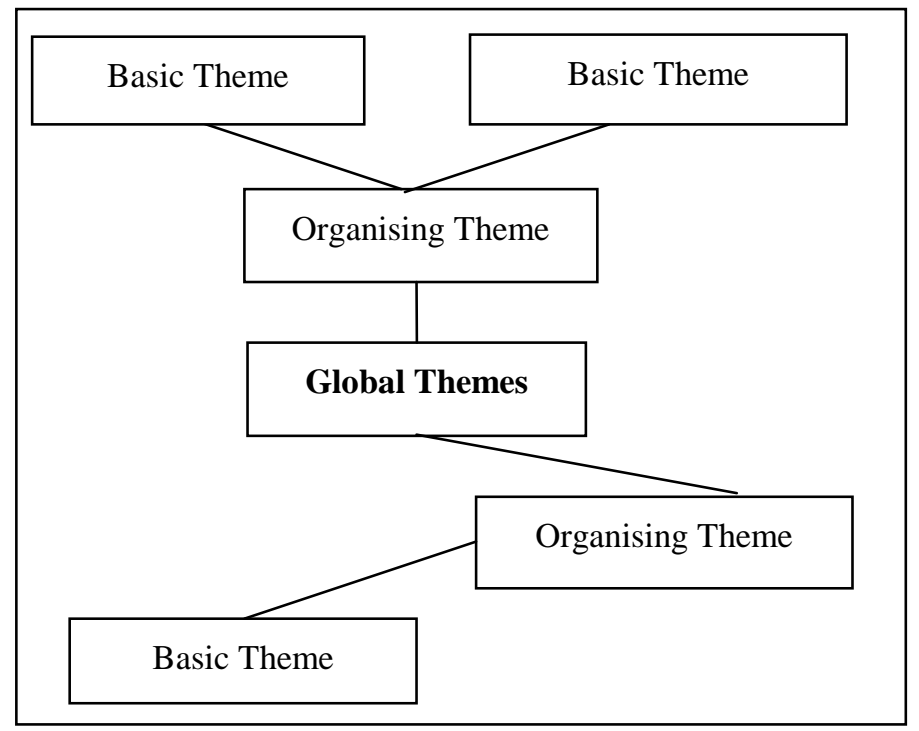

Figure 1. Web Themes

Analysis of data includes the following 5 steps [6]: Step 1. Code Material (a) Devise a coding framework (b) Dissect text into text segments using the coding framework Step 2. Identify Themes (a) Abstract themes from coded text segments (b) Refine themes. Step 3. Construct Thematic Networks (a) Arrange themes (b) Select Basic Themes (c) Rearrange into Organizing Themes (d) Deduce Global Theme(s) (e) Illustrate as thematic network(s) (f) Verify and refine the network(s). Step 4. Describe and Explore Thematic Networks (a) Describe the network (b) Explore the network. Step 5. Summarize Thematic Networks

\section{RESULTS AND DISCUSSION}

The results and discussions of the study will be categorized under three core themes identified in the focus group interview (i) students' awareness (ii) students understanding on learning outcomes (iii) becoming Independent learner.Some representative excerpts elicited from the verbatim are presented for each theme.

\section{A Awareness and Attitudes on LMS}

25 out of 25 participants in the study were aware of the use of LMS in some of their courses. It is shown from the excerpts extracted below.

" hmm...Yes, I am aware of the My LMS usage in IIUCS campus. This semester we have three major subjects where the lecturers had made use of MyLMS in their subject delivery. There's one lecturer..our Prof is very reminding us that her mode of delivery will be face to face and online via MyLMS”. (Participant1)

"Of course I do. On the first day of the lesson, my lecturer said; I shall use MyLMS to make an announcement, to upload teaching materials and course outline, videos and much more. Be mindful that, I am not providing you any handouts about this course...everything online...Useful related reading materials courses like Teacher Dynamics, Introduction to Linguistics, Educational Technology videos, Testing and Evaluation notes were uploaded in MyLMS....So..hmm yes I am aware of LMS". (Participant 16)

"I have no problem accessing MyLMS from Library or the University mosques. So usually I do work or assignments from there...". (Participant 4)

" I like online learning...I can access at my convenient time. I go online for LMS at least two times daily...It depends too if new announcements pop up. The grade book in LMS is helpful .. it keeps me informed on my progress and grades...”. (Participant 9)

"I like the idea, oh having online quizzes and online forums". (Participant 18)

\section{B Students' Understanding on Learning Outcomes}

23 out of 25 participants understood what is meant by Learning Objectives (henceforth LO). In short, the participants explained that $\mathrm{LO}$ is what is expected to achieve after the 14 weeks of the course.

" in this semester, we signed up for four courses amounting 12 credit hours. Each of this courses, the lecturer explains the learning outcomes...hmmm yes the LO, one of our pedagogy lecturers explained one by one of the LO and mentioned she puts up in MyLMS". (Participant 12)

"the LO are included in the course proforma, the upper sections, all the LOs are explained... We are reminded to be mindful about what to be expected of us from the class...". (Participant 10) 
Evidently, all the participants are mindful and positive about the learning outcomes of the courses which they registered.

\section{Becoming Independent Learners}

All the participants came to an agreement that the integration of LMS in the courses to some extent has made them becoming an independent learner.

"Being independent..hmm I would agree because..it gives me more independence. Even though physically my lecturer is not around but the resources that were put up is enough for me to move on with the assignments...". (Participant 5)

"I am now 20 yrs old...I cant' be depending so much on my teacher like my school days... Learning via MyLMS is providing me some training to be independent. I like it...”. (Participant 15)

"Postings opinions and views online is good too. Like me and my friends...when our lecturer asked for opinions, we hardly participated...but when it comes to posting views online we are braver...". (Participant 20)

"I become more confident in expressing my ideas using communication technologies such as in the online forum. We also uploaded our videos and yeah...interesting...I see myself and my groups are more independent. If our lecturer has meeting or seminars, she posted some resources via LMS, and we will be interacting in the forum. We do not need to replace classes...I agree, and we all do that it molded us to be an independent learner...hmm, but I must say not $100 \%$ independent...some guidance from the lecturers is still required". (Participant 24)

\section{CONCLUSION AND SUMMARY}

A study was conducted to learn about students' attitude towards using a Learning Management system (MyLMS) and their awareness of where and how learning outcomes are used. The focus group interview included three categories: Awareness and Attitudes, Students Understanding on Learning Outcomes and Becoming An Independent Learner. Results showed that the majority of the students are aware and has positive attitudes on LMS usage, understood the learning outcomes specified in the Course Proforma. Furthermore, students agreed in the training of using LMS they are molded into becoming an independent learner which they appreciate in their event of learning. In conclusion, most students felt they became more confident in expressing their opinions and ideas using communication technologies. Furthermore, while the available web resources allowed them to become independent learners they still needed the guidance of instructors. The knowledge gained from this research could contribute to understanding the online modality of education in this region and help instructors select the most appropriate technological methods to improve learning in a segregated educational environment.

\section{REFERENCES}

[1] R. Kaur and G. K. Sidhu, "Learner autonomy via asynchronous online interactions: a Malaysian perspective," Int. J. Educ. Dev. Using Inf. Commun. Technol., vol. 6, no. 3, p. 88, 2010.

[2] R. K. Ellis, "Field guide to learning management systems," ASTD Learn. Circuits, 2009.

[3] T. T. Dang and M. Robertson, "Impacts of learning management system on learner autonomy in EFL learning," Int. Educ. Stud., vol. 3, no. 3, p. 3, 2010.

[4] C. Balcikanli, "Learner Autonomy in Language Learning: Student Teachers' Beliefs.," Aust. J. Teach. Educ., vol. 35, no. 1, pp. 90-103, 2010.

[5] J. W. Creswell, Qualitative inquiry and research design: Choosing among five approaches. Sage publications, 2012.

[6] H. Freitas, J. Moscarola, and M. Jenkins, "Content and lexical analysis: a qualitative practical application," ISRC, Merrick Sch. Business, Univ. Balt. (MD, EUA), WP ISRC, no. 070498, p. 35, 1998. 